\title{
¿UAS Current Mapping: A Wave-Based Heading and Position Correction
}

\author{
Buörn Lund, ${ }^{a}$ Ruben CARrasco, ${ }^{\mathrm{b}}$ Hanjing Dai, ${ }^{\mathrm{a}}$ Hans C. Graber, ${ }^{\mathrm{a}}$ CÉdric M. Guigand, ${ }^{\mathrm{a}}$ Brian K. Haus, ${ }^{\mathrm{a}}$ \\ Jochen Horstmann, ${ }^{\mathrm{b}}$ John A. Lodise, ${ }^{\mathrm{a}}$ GuIllaume Novelli, ${ }^{\mathrm{a}}$ TAMAy ÖZGÖKMEN, ${ }^{a}$ Michael A. RebOzO, ${ }^{a}$ \\ EDWARD H. RYAN, ${ }^{\mathrm{a}}$ AND MICHAEL STREßER ${ }^{\mathrm{b}}$ \\ ${ }^{\text {a }}$ Rosenstiel School of Marine and Atmospheric Science, University of Miami, Miami, Florida \\ ${ }^{\mathrm{b}}$ Helmholtz Zentrum Geesthacht, Geesthacht, Germany
}

(Manuscript received 29 July 2020, in final form 8 June 2021)

\begin{abstract}
Our unmanned aerial system (UAS) current mapping is based on optical video data of the sea surface. We use three-dimensional fast Fourier transform and least squares fitting to measure the surface waves' phase velocities and the currents via the linear dispersion relationship. Our UAS is a low-cost off-the-shelf quadcopter with inaccurate camera position and attitude measurements, which may cause spurious currents as large as the signal. We present a novel wavebased UAS heading and position correction, improving the image rectification accuracy by a factor of $\sim 3.5$ and the current measurements' temporal repeatability by factors of 1.8-4.8. This validation study maps the currents at high spatiotemporal resolution ( $5 \mathrm{~m}$ and $4 \mathrm{~s}$ ) across the $\sim 700$-m-wide tidally dominated Bear Cut channel in Miami, Florida. The UAS currents are compared to flotsam tracks, obtained through automated UAS video object detection and tracking, drifter tracks, and acoustic Doppler current profiler measurements. The root-mean-square errors of the cross- and along-channel currents are better than $0.03 \mathrm{~m} \mathrm{~s}^{-1}$ for the flotsam comparison and better than $0.06 \mathrm{~m} \mathrm{~s}^{-1}$ for the drifter comparison; the latter revealed a $0.06 \mathrm{~m} \mathrm{~s}^{-1}$ along-wind bias due to wind- and wave-driven vertical current shear. UAS current mapping could be used to monitor river discharge, buoyant pollutants, or submesoscale fronts and eddies; the proposed wave-based heading and position correction enables its use in areas without ground control points.
\end{abstract}

KEYWORDS: Currents; Dispersion; Small scale processes; Waves, oceanic; Aircraft observations; Remote sensing

\section{Introduction}

Unmanned aerial systems (UASs) equipped with gimbaled high-quality video cameras have in recent years become readily accessible to hobbyists and professionals alike. Scientists from various fields have embraced the technology due to its low cost, versatility, and ease of operation. Science applications include environmental monitoring, precision agriculture, and traditional surveying (Colomina and Molina 2014). At the coast, UAS-based structure from motion (SfM) photogrammetry, yielding three-dimensional (3D) elevation maps from a set of overlapping pictures, has been widely used to measure dune and beach erosion (e.g., Mancini et al. 2013; Turner et al. 2016). The same method has been applied to shallow aquatic habitats with the aid of fluid lensing (Chirayath and Earle 2016). UASs have furthermore been used to characterize the surf zone (Holman et al. 2017), yielding the same imaging products as landbased Argus stations (Holman and Stanley 2007), namely, time series of wave run up on a beach (Holman and Guza 1984), timeexposure images for the identification of nearshore sand bars and rip channels (Lippmann and Holman 1989), the intertidal beach profile (Plant and Holman 1997), and alongshore currents from the tracking of persistent sea foam (Chickadel et al. 2003).

This study derives currents from the surface wave signal within Fourier-transformed series of rectified UAS optical

¿ Denotes content that is immediately available upon publication as open access.

Corresponding author: Björn Lund, blund@cstars.miami.edu images, building on earlier studies that date back to the 1980s. Young et al. (1985) were the first to propose a 3D fast Fourier transform (FFT) based wave and current measurement technique, which they applied to series of marine X-band radar (MR) sea surface backscatter intensity images. In the resulting wavenumber frequency power spectra, the surface wave signal is located on the "dispersion shell." It is given by the linear wave dispersion relationship

$$
\omega=\sqrt{g k \tanh (k h)}+\mathbf{k} \cdot \mathbf{U},
$$

where $\omega$ is the angular frequency, $g$ the acceleration due to gravity, $k=|\mathbf{k}|$ the wavenumber magnitude, $h$ the water depth, and $\mathbf{U}$ the current vector. Both the current vector and the water depth can be determined from the wave signal's spectral coordinates through a least squares fit that minimizes the coordinates' distance from the dispersion shell (Bell 1999; Senet et al. 2001). Dugan et al. (2001) and Piotrowski and Dugan (2002) first applied this method to optical image series of shoaling surface waves collected from an aircraft. An alternative wavebased bathymetry retrieval method uses gradients within singlefrequency phase images. The open source cBathy algorithm is a widely used implementation of the phase-based method (Holman et al. 2013); it has been applied to both optical and MR image series (e.g., Bergsma et al. 2016; Honegger et al. 2019).

The sea surface radiance measured by the UAS camera has contributions from reflected sky radiance, upwelled radiance from the water column, and sun glitter; all three are modulated by the surface waves (e.g., Chapman and Irani 1981; Jähne and Riemer 1990; Rascle et al. 2017). Reflected sky radiance increases exponentially from nadir to horizontal viewing angles, 
upwelled radiance is largely independent of the viewing angle, and sun glitter centers around the mirror image of the sun. Outside of the sun glitter region, reflected sky radiance dominates near the horizon and upwelled radiance dominates near nadir (Plass et al. 1976; Walker 1994). Here, the scattering mechanisms are relevant only insofar as they relate to the wave contrast; they do not affect the wave signal's location on the linear dispersion shell (Dugan et al. 2001).

High-resolution current maps can be used to monitor the transport of buoyant pollutants (e.g., oil spills) and sediments, surfzone dynamics (e.g., rip currents), river discharge, or submesoscale fronts and eddies. Previous UAS studies have used optical flow and cross-correlation techniques among others to track surface tracers such as foam, leaves, or dye (Brouwer et al. 2015; Tauro et al. 2016; Dérian and Almar 2017; Jung et al. 2019; Pearce et al. 2020). UAS wave-based current mapping has the advantage that it only relies on surface gravity waves, which are ubiquitous in oceans, lakes, and rivers. Yet the technique remains largely unexplored in the literature; the only published study is by Streßer et al. (2017), who used a DJI Phantom 3 (P3) quadcopter to retrieve the currents of the river Elbe in Lauenburg, Germany. They based their study on $60 \mathrm{~s}$ of video, which they recorded while hovering at an altitude of $\sim 200 \mathrm{~m}$ with the camera at nadir. Their current retrieval was based on wavelengths from 0.1 to $1 \mathrm{~m}$, which is two orders of magnitude shorter than the waves that are typically used for bathymetry retrieval (e.g., Bell 1999; Holman et al. 2013). A comparison with reference measurements from an acoustic Doppler current profiler (ADCP) yielded root-mean-square (RMS) errors of $0.09 \mathrm{~m} \mathrm{~s}^{-1}$ with no bias. They did not investigate the impact of UAS camera position $(x, y$, and $z$ coordinates) and attitude (pitch, roll, and heading) errors on their current measurements; considering their current measurements' long averaging period (60 s), they assumed UAS station keeping errors to be negligible.

UAS wave-based bathymetry retrieval has also been little explored in the literature. Holman et al. (2017) retrieved bathymetry from UAS optical image series of the surf zone at Duck, North Carolina. More recently, Bergsma et al. (2019) used a similar approach to retrieve bathymetry in Saint-Louis, Senegal, and Brodie et al. (2019) deployed a multicamera UAS at two sites to simultaneously measure SfM coastal topography and bathymetry. All three studies used cBathy and relied on ground control points (GCPs) to correct UAS station keeping errors; the resulting bathymetries were in good agreement with survey and Argus data. Last, Sun et al. (2019) used particle image velocimetry (PIV) to measure wave celerity and invert bathymetry from UAS surfzone images. Their UAS autopilot was capable of accurate station keeping, allowing them to forego GCPs. However, bathymetry measurements are less sensitive to image rectification errors than current measurements, as they are based on longer waves that can "feel" the bottom (Dugan et al. 2001).

To examine the station keeping accuracy of their P3 quadcopter, Holman et al. (2017) set its autopilot to hover at a specific position and attitude while recording video over periods of 3-16 min. The camera field of view (FOV) covered four noncollinear GCPs; by minimizing the distance between the measured and predicted GCP image coordinates, they were able to generate time series of the "true" camera position and attitude. This works best if GCPs are distributed uniformly across the camera FOV or along all edges; a sparse GCP distribution, which is common for coastal applications, will reduce the photogrammetric accuracy (Martínez-Carricondo et al. 2018). Holman et al. (2017) reported excellent P3 station keeping with standard deviations of $0.2-0.5 \mathrm{~m}$ and $0.2^{\circ}-0.4^{\circ}$ in camera position and attitude. However, the horizontal position, pitch, and roll were better constrained than altitude and heading. During the first $2 \mathrm{~min}$ of one representative flight, they observed altitude and heading changes greater than $1 \mathrm{~m}$ and $2^{\circ}$. Also using a P3, Bergsma et al. (2019) found comparable standard deviations, but noted concerning drifts in UAS position and attitude of $\pm 1.5 \mathrm{~m}$ and $\pm 1.5^{\circ}$. Adding to these issues, Brouwer et al. (2015) found that the horizontal station keeping capabilities of their Aerialtronics Altura AT6 and 3D Robotics Y6 hexacopters deteriorated as the wind speed increased from 2.5 to $5.4 \mathrm{~m} \mathrm{~s}^{-1}$.

Here, we present UAS, ADCP, and drifter current measurements from Bear Cut channel in Miami, Florida. Our goals are twofold: First, we demonstrate that UAS heading and position errors can produce apparent motions that are on the same order of magnitude as the current signal itself. We propose a novel method to correct errors in UAS heading and position. Apparent motions due to pitch and roll errors are assumed to be negligible for the flight altitude and nadir viewing angle used here; this assumption is reasonable if pitch and roll are measured with an accuracy of $0.2^{\circ}$. The method is based on the wave signal only, it does not require GCPs. This is important because most of our UAS video data do not contain land. A small fraction of the imagery contains land and sea, including a large number of fixed objects with prominent corners at or near sea level. To validate the wave-based heading and position correction, we track these fixed objects through a combination of corner detection and optical flow techniques. The fixed object tracks are used to infer the "true" UAS heading and position changes, which serve as a reference for our wave-based solution. Second, we aim to generate UAS current maps across the $\sim 700 \mathrm{~m}$-wide channel during ebb and flood tides. By basing our method on short waves of $\sim 0.5-5 \mathrm{~m}$ (or $\sim 0.5-2 \mathrm{~s}$ ), we obtain currents at a high spatiotemporal resolution ( $5 \mathrm{~m}$ and $4 \mathrm{~s}$, with $\sim 50 \%$ oversampling) corresponding to the near surface (effective depth of $\sim 0.03 \mathrm{~m}$ ). The results are validated against the ADCP and drifter data. We furthermore identify and track flotsam within the UAS imagery; the flotsam tracks provide an alternative means of validation.

This paper is organized as follows: Section 2 describes the Bear Cut experiment and datasets this study draws from. Section 3 introduces the wave-based UAS motion correction and current mapping methods. We assess the methods' accuracies and present results in section 4 . The paper closes with a discussion (section 5) and conclusions (section 6).

\section{Data overview}

The Bear Cut UAS experiment was conducted from 19 to 23 February 2018 by the Consortium for Advanced Research 
on Transport of Hydrocarbon in the Environment (CARTHE) in collaboration with the Center for Southeastern Tropical Advanced Remote Sensing (CSTARS) and Helmholtz Zentrum Geesthacht (HZG). Bear Cut is a tidally dominated channel connecting Biscayne Bay and the Atlantic Ocean. Located off the coast of Miami, Florida, it separates Virginia Key from Key Biscayne, two barrier islands connected to the mainland via the Rickenbacker Causeway and Bear Cut bridges. The experiment's goal was to characterize the surface flow across Bear Cut using UAS optical video data. Streßer et al. (2017) have successfully applied UAS wave-based current mapping to a river; this study applies the technique to the coastal ocean, with a new focus on the method's sensitivity to UAS heading and position errors.

The UAS used here is a DJI Phantom 4 Pro (P4), a low-cost off-the-shelf quadcopter popular with both recreational users and researchers. It offers a maximum flight time of $30 \mathrm{~min}$ and maximum wind speed resistance of $10 \mathrm{~m} \mathrm{~s}^{-1}$. Its camera uses a 1 in. $(2.54 \mathrm{~cm})$ complementary metal oxide semiconductor (CMOS) sensor, capable of capturing video of up to $4096 \times 2160$ pixels at $60 \mathrm{fps}$ with a maximum bitrate of $100 \mathrm{Mbps}$. The camera attitude is stabilized by a three-axis gimbal, which keeps roll (rotation about the heading axis) at $0^{\circ}$ and allows the user to select a pitch from $-90^{\circ}$ (nadir) to $30^{\circ}$ (the view is horizontal at $0^{\circ}$ ). The gimbal's angular control accuracy is $0.02^{\circ}$. The aircraft's navigational equipment includes a GPS and Global Navigation Satellite System (GLONASS), a barometer, an inertial measurement unit (IMU), and a magnetic compass. The manufacturer's stated hover accuracy with GPS positioning is $1.5 \mathrm{~m}$ horizontally and $0.5 \mathrm{~m}$ vertically. Time series of flight data, including camera position, attitude, and actions, are automatically recorded to the aircraft's internal storage (DJI 2017b). In this study, the camera was set to capture video of $3840 \times 2160$ pixels at $29.97 \mathrm{fps}$ with H.264 encoding. Flight missions were planned and executed using Litchi software operated in waypoint mode (VC Technology 2020).

Figure 1 shows a map of the experiment layout. The coordinate system used throughout this study has been rotated by $45^{\circ}$ (clockwise from north), with $x$ denoting the cross-channel coordinate (increasing toward Key Biscayne) and $y$ denoting the along-channel coordinate (increasing toward Biscayne Bay). The coordinate system's origin coincides with the UAS launch location on the roof of the Doherty Marine Science Center at the Rosenstiel School of Marine and Atmospheric Science (RSMAS).

This study focuses on two UAS flights from 1335 to 1350 EDT 22 February 2018 (hereon referred to as F1) and from 1653 to 1710 EDT (F2). Both flights followed the same automated mission consisting of 9 UAS current mapping stations. At each station, the UAS was programmed to hover for $\sim 30 \mathrm{~s}$ at an altitude of $\sim 74.5 \mathrm{~m}$ and record video with the camera at nadir and oriented upchannel (toward the Atlantic Ocean). The stations span $\sim 700 \mathrm{~m}$ across Bear Cut (south of Bear Cut bridge), from the RSMAS beach on Virginia Key to the entrance of Crandon Marina on Key Biscayne. They were positioned such that the FOVs of neighboring stations have $\sim 25 \%$ overlap (see Fig. 1). The video data are used not only

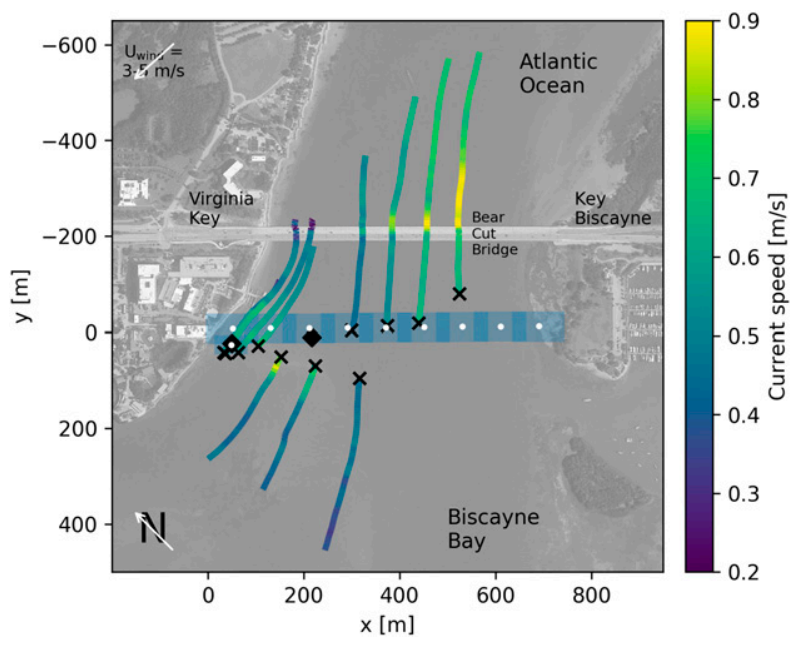

FIG. 1. Map of Bear Cut channel with the UAS horizontal positions and camera footprints of each current mapping station marked by dots and partially transparent rectangles. The drifter launch locations are marked by crosses, and their tracks and speeds are given by colored lines. The drifters moving into Biscayne Bay (downward) were launched from 1149 to 1152 EDT 22 Feb 2018; the drifters moving to the Atlantic Ocean (upward) were launched from 1626 to 1700 EDT 22 Feb 2018. The diamonds mark the two ADCP locations. The UAS launch site is located at the coordinate system's origin. The background image is from 17 Dec 2018, (C)2020 Google.

for the wave-based current mapping, but also to track floating Sargassum, driftwood, and other debris.

The UAS data are complemented by drifter, ADCP, and wind measurements. The drifters were developed by CARTHE and consist of a torus float with an integrated GPS and battery, two interlocking drogue panels of $0.4 \mathrm{~m} \times 0.4 \mathrm{~m}$, and a $0.2 \mathrm{~m}$ chain link. The drogue and float are made of a biopolymer to reduce their environmental footprints (Novelli et al. 2017). The drifters were set to acquire GPS positions at $1 \mathrm{~Hz}$ and launched and recovered from a small boat. Drifter velocities are computed from position fixes that are spaced $15 \mathrm{~s}$ apart. Figure 1 shows three drifter tracks from a flood tide (to Biscayne Bay) launched on 1149 to 1152 EDT 22 February 2018, and eight drifter tracks from an ebb tide (to the Atlantic Ocean) launched on 1626 to 1700 EDT 22 February 2018 (two drifters were launched side-by-side, their tracks are difficult to distinguish in the figure). Only the drifters from the latter launch collocate with the UAS current maps.

The bottom-mounted uplooking ADCP used during the experiment was a Nortek Aquadopp $2 \mathrm{MHz}$ with an internal sampling rate of $23 \mathrm{~Hz}$ (Nortek 2017). Each ADCP current profile was based on 2 min of acoustic pulses; for every half hour the ADCP sampled the first $22 \mathrm{~min}$ and slept the remaining $8 \mathrm{~min}$. The ADCP acquired current profiles with $0.1 \mathrm{~m}$ resolution and a blanking distance of $0.2 \mathrm{~m}$. It was deployed at $(x=217 \mathrm{~m}, y=10 \mathrm{~m})$ in a depth of $4.6 \mathrm{~m}$ from 1110 to 1430 EDT 22 February 2018 (i.e., during F1) and at $(x=50 \mathrm{~m}$, $y=23 \mathrm{~m}$ ) in a depth of $4.2 \mathrm{~m}$ from 1452 EDT 22 to 1210 EDT 23 February 2018 (i.e., during F2). For F1, the UAS camera 
FOV at the third station overlapped with the ADCP. For F2, a tenth current mapping station, with the UAS hovering for $\sim 100 \mathrm{~s}$ at a height of $47.2 \mathrm{~m}$ and the camera recording video at nadir, had to be added to ensure overlap with the ADCP (see Fig. 1). Last, this study uses wind speed and direction measurements from an anemometer mounted on the roof of the Science Laboratory and Administration building at RSMAS.

\section{Methodology}

\section{a. Camera calibration and image rectification}

For the quantitative analysis of our UAS video data, we must know the photogrammetric transformation between 3D world and two-dimensional (2D) image coordinates. This requires two parameter sets: The first set is the camera position and attitude, also referred to as extrinsic camera parameters. They are recorded by the P4's GPS, barometer, IMU, gimbal, and compass. The second set is the camera's focal length $\left(f_{U}, f_{V}\right)$ and optical center $\left(U_{0}, V_{0}\right)$, also referred to as intrinsic camera parameters. Being unique to a specific camera, they need to be calculated only once (assuming a fixed focal length). The intrinsic camera parameters form the camera matrix

$$
\mathbf{A}=\left[\begin{array}{ccc}
f_{U} & 0 & U_{0} \\
0 & f_{V} & V_{0} \\
0 & 0 & 1
\end{array}\right]
$$

Disregarding camera distortion, the transformation from world to image coordinates is given by the pinhole camera model

$$
s \mathbf{p}=\mathbf{A}[\mathbf{R} \mid t] \mathbf{P}_{w},
$$

where $s$ is an arbitrary scaling factor, $\mathbf{p}$ is a $2 \mathrm{D}$ point in homogeneous image coordinates, $[\mathbf{R} \mid t]$ is a homogeneous transformation matrix, and $\mathbf{P}_{w}$ is a $3 \mathrm{D}$ point in homogeneous world coordinates. $[\mathbf{R} \mid t]$ encodes the extrinsic parameters and represents a joint rotation and translation (Heikkila and Silven 1997; Zhang 2000).

Although the P4 camera uses a low distortion lens, straight lines may appear slightly curved at the outer image edges. There are two main types of camera distortion: Radial distortion is due to camera lens asymmetries and increases with distance from the optical center; tangential distortion is due to misalignments between the lens and the image plane (Wang et al. 2008). The image calibration technique used here requires images of a calibration pattern (e.g., a chess board with known square size) taken at different locations and orientations. It estimates the intrinsic camera parameters and 5 distortion coefficients; the latter are needed to correct radial and tangential distortions (Bouguet 2004). Figure 2 shows a rectified UAS image from F1's first current mapping station; the image edges are slightly curved due to camera distortion. The image undistortion and rectification are accomplished in a single step by bilinear interpolation.

\section{b. Current mapping}

The basics of the wave-based current mapping have already been explained: We first Fourier transform a series of rectified UAS optical images into wavenumber-frequency space,

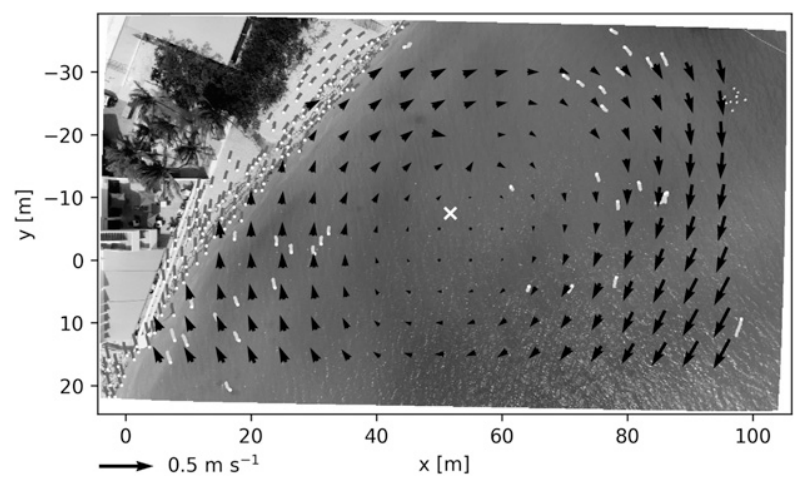

FIG. 2. Rectified UAS grayscale image from 1336:51 EDT $22 \mathrm{Feb}$ 2018. The black arrows mark the UAS wave-based apparent currents from the first current mapping station and analysis period (of which the image shows the first frame). The arrow key is given in the bottom left. The light and dark gray lines mark flotsam and fixed object tracks over the same analysis period, with the white dots corresponding to their locations within the shown image. The UAS camera's horizontal position is marked by a white cross.

identify the wave signal, and then use a least squares optimization to find the current that minimizes the wave signal's distance from the dispersion shell (Young et al. 1985). The method requires a wave signal with significant directional spread to measure the full current vector; this condition is generally fulfilled by natural sea states (e.g., Rogers and Wang 2007). An error model to estimate the method's measurement accuracy is given by Senet et al. (2001).

The main challenge lies in identifying the wave signal within the wavenumber frequency power spectrum, which can be difficult to distinguish from the background noise. It requires a good understanding of the wave signal's higher harmonics, aliasing effects due to spatial or temporal undersampling (Senet et al. 2001), and the quasi-linear low-frequency feature, that has been attributed to the drift of small foam patches (Dugan and Piotrowski 2003), geometric shadowing (Seemann et al. 1997), and wave breaking caused by long wave interference (Plant and Farquharson 2012). The standard method uses global threshold values to identify the wave signal (Young et al. 1985; Senet et al. 2001). This has the disadvantage that the resulting spectral coordinates are unevenly clustered around the dispersion shell, which introduces biases in the currents. It furthermore misses the relatively weak high-wavenumber signal, which is more sensitive to currents as it exhibits larger Doppler shifts [see Eq. (1)].

Here, we begin by transforming the wavenumber frequency power spectrum from Cartesian to polar coordinates (i.e., from $k_{x}-k_{y}-\omega$ to $\theta-k-\omega$ space, where $\theta$ is the direction). We then empirically determine the background noise, assuming that it is a function of $k$ and $\omega$ only. (Specifically, we mask the coordinates on the zero-current dispersion shell, take the median over all directions, fill data gaps through polynomial interpolation, and convolve the resulting image with a Gaussian smoothing kernel.) Dividing the wavenumber frequency power spectrum by the background noise, we obtain a wavenumber frequency signal-to-noise ratio (SNR) spectrum. At each direction $\theta$ and 
frequency $\omega$, we find the wavenumber $k$ with the maximum SNR, skipping coordinates where SNR $<1.5$. To determine the peak wavenumber more precisely, we fit a second-order polynomial to the SNR peak and the two values on either side of it, and retain the resulting parabola's peak wavenumber. The use of a polar coordinate system thus allows us to be more selective in our choice of spectral coordinates and avoid inherent biases in the standard method; the power to SNR spectrum transform facilitates the highwavenumber signal identification. We then analyze the coherence of the selected spectral coordinates to reject outliers. Finally, Eq. (1) is least squares fitted to the wave signal to obtain the current.

The current mapping is performed across the entire UAS camera FOV on a horizontal grid of $5 \mathrm{~m} \times 5 \mathrm{~m}$. The circular analysis windows, centered around each grid point, have a radius of 128 pixels corresponding to $7.3 \mathrm{~m}$ ( or $4.6 \mathrm{~m}$ for station 10 of F2) with a resolution of $0.06 \mathrm{~m} \times 0.06 \mathrm{~m}$ (or $0.04 \mathrm{~m} \times 0.04 \mathrm{~m}$ for station 10 of $\mathrm{F} 2$ ). In practice, each analysis window is a $256 \times 256$ pixel square where pixels outside the circle inscribing the square are masked. Analysis windows that are partially outside the camera FOV are discarded. This study uses 256 video frames per analysis, which corresponds to an analysis period of $8.5 \mathrm{~s}$, and makes a new current measurement every $4 \mathrm{~s}$. Hence, we take eight current measurements per station and analysis period (or 25 current measurements for station 10 of F2). The maximum spatial overlap between neighboring analysis windows is $57.2 \%$ (or $34.6 \%$ for station 10 of F2). The maximum temporal overlap between neighboring analysis periods is $53.2 \%$. The UAS current maps are quality controlled by evaluating each measurement's spatiotemporal similarity with its neighbors (i.e., the absolute difference from the median of all neighbors); measurements that exceed a certain similarity threshold are discarded. Figure 3 shows a flowchart depicting the current mapping method. The same method has already been applied to shipboard MR data from the Gulf of Mexico (Lund et al. 2018, 2020).

The wave-based current is an exponentially weighted average over the upper ocean current profile, with surface currents carrying the greatest weight (Stewart and Joy 1974):

$$
\mathbf{U}(k)=2 k \int_{0}^{h} \mathbf{U}(z) \exp (-2 k z) d z .
$$

This means that the current measurement's effective depth increases with the length of the waves on which it is based, which can be exploited to measure upper ocean vertical shear (Lund et al. 2015b; Campana et al. 2016, 2017; Smeltzer et al. 2019). For the special cases of a linear and exponential profile, the effective depths are $7.8 \%$ and $4.4 \%$ of the underlying wavelengths (Ha 1979; Stewart and Joy 1974). Here, the current fit is limited to wavenumbers of 1 to $20 \mathrm{rad} \mathrm{m}^{-1}$ (i.e., wavelengths of $6.28-0.31 \mathrm{~m})$. The mean wavenumbers for $\mathrm{F} 1$ and $\mathrm{F} 2$ are 9.9 and $9.1 \mathrm{rad} \mathrm{m}^{-1}(0.63$ and $0.69 \mathrm{~m})$ with 5th percentiles of 2.8 and $2.9 \mathrm{rad} \mathrm{m}^{-1}(2.44$ and $2.17 \mathrm{~m})$ and 95th percentiles of 18.7 and $17.5 \mathrm{rad} \mathrm{m}^{-1}(0.34$ and $0.36 \mathrm{~m})$. If we assume an exponential current profile, a reasonable assumption based on recent field measurements (Laxague et al. 2018), the effective depths corresponding to the mean wavenumbers are both $0.03 \mathrm{~m}$. (For a linear current profile, they are both $0.05 \mathrm{~m}$.)

Bear Cut has a complex bathymetry consisting of several shoals and a navigational channel flanking Key Biscayne and leading to Crandon Marina. A bathymetric survey of Bear Cut (north of Bear Cut bridge) from 2011 observed water depths between 1 and $7 \mathrm{~m}$ (MacMahan et al. 2012). As a rule of thumb, a wave penetrates the upper ocean down to a depth of approximately half its length (Dean and Dalrymple 1991). For wave-based bathymetry mapping, a more practical limit lies between $\sim 1 / 3$ and $1 / 4$ of the wavelength, where waves experience a $\sim 5 \%-10 \%$ change in their wavelength (Bell and Osler 2011; Lund et al. 2020). Here, the 5th percentiles of the wavenumbers contributing to the current fit would start "feeling" the bottom at water depths of $0.8 \mathrm{~m}$ or less. We can therefore safely assume that the waves encountered in this study obey the deep water dispersion relationship.

\section{c. Heading and position correction}

For each current mapping analysis period, we rectify the UAS video data using the mean camera position and attitude; the instantaneous measurements are too noisy and imprecise, their use would result in less stable images. Any deviation of the UAS camera position and attitude from the mean will introduce an artificial current. The current mapping thus yields the apparent motion at each grid point, which can be expressed as $(\check{u}=u+\hat{u}, \check{v}=v+\hat{v})$, with $(u, v)$ being the current velocity and $(\hat{u}, \hat{v})$ being the motion vector due to UAS station keeping errors. The current velocity can be further decomposed into mean flow, turbulent fluctuations, and wave orbital motions; this study considers only the mean flow. In absence of GCPs, we must either rely on the UAS autopilot's accurate station keeping ability or estimate and remove $(\hat{u}, \hat{v})$ from our measurements. Here, we follow the latter option by proposing a method that inversely determines UAS position and attitude changes by assuming temporally stationary currents.

A UAS horizontal motion results in an apparent motion of the same magnitude and opposite direction. With the camera at nadir, disregarding camera distortion, a UAS vertical motion and heading change result in apparent motions that increase linearly with distance from the horizontal camera position, with the former being in the radial and the latter in the azimuthal direction. A UAS vertical motion may furthermore affect the current mapping through the associated image resolution change, which we neglect for the sake of simplicity. The effects of UAS heading and position changes on the camera FOV can be described by an affine transformation

$$
\left[\begin{array}{l}
x^{\prime} \\
y^{\prime}
\end{array}\right]=\left[\begin{array}{l}
x-x_{0} \\
y-y_{0}
\end{array}\right]\left[\begin{array}{ccc}
\cos (\psi) s & -\sin (\psi) s & t_{x} \\
\sin (\psi) s & \cos (\psi) s & t_{y}
\end{array}\right],
$$

where $x_{0}$ and $y_{0}$ represent the horizontal camera position, $t_{x}$ and $t_{y}$ a translation (horizontal motion), $s$ an expansion (or scaling factor, indicative of vertical motion), and $\psi$ a rotation (heading change). The motion vector due to UAS 

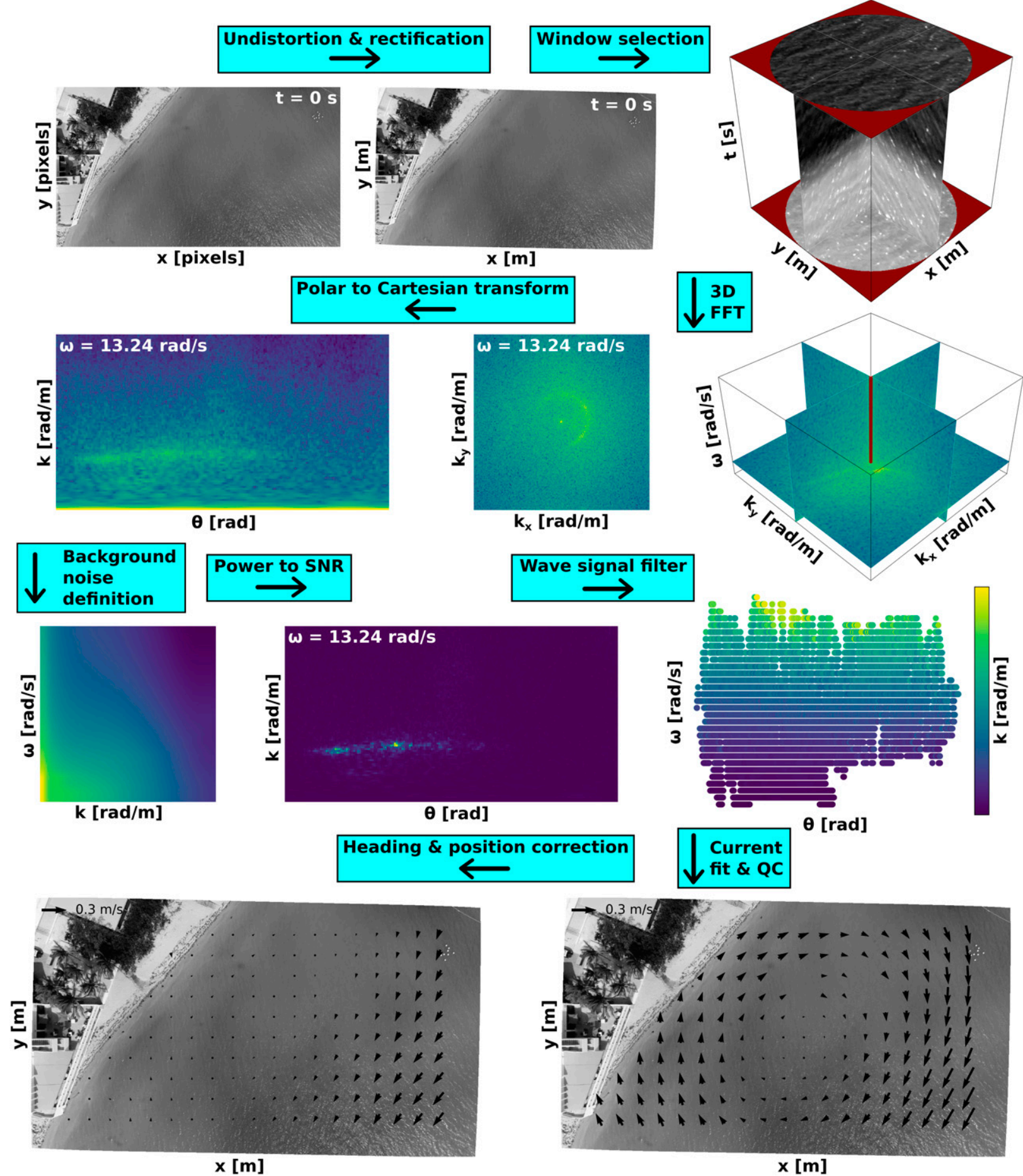

FIG. 3. Flowchart diagram depicting the current mapping method, using data from the first analysis period of F1 and the analysis window at $(50 \mathrm{~m},-5 \mathrm{~m})$ as example.

station keeping errors is thus given by $\left(\hat{u}=\left(x-x_{0}-x^{\prime}\right) / T\right.$, $\left.\hat{v}=\left(y-y_{0}-y^{\prime}\right) / T\right)$, with $T$ being the analysis period; $(\hat{u}, \hat{v})$ must be subtracted from $(\check{u}, \check{v})$ to obtain $(u, v)$.

For example, at a distance of $50 \mathrm{~m}$ from the camera, a $1^{\circ}$ rotation over $8.5 \mathrm{~s}$ (our analysis period) would result in an error of $0.10 \mathrm{~m} \mathrm{~s}^{-1}$. If the UAS changed its altitude from 74.5 to $75.5 \mathrm{~m}$, the corresponding error would be $0.08 \mathrm{~m} \mathrm{~s}^{-1}$. Such errors can be on the same order of magnitude as the signal and must be accounted for. Figure 2 shows a map of the apparent currents from F1's first analysis period, with speeds from 
0.01 to $0.32 \mathrm{~m} \mathrm{~s}^{-1}$ (mean of $0.14 \mathrm{~m} \mathrm{~s}^{-1}$ ); only vectors that passed the spatiotemporal quality control are plotted. It shows an anticyclonic "eddy" whose center coincides with the horizontal camera position; the fixed object tracks included in the figure indicate that this "eddy" is in fact due to an unaccounted for counterclockwise UAS camera rotation.

Our UAS heading and position correction is based on the assumption that currents are stationary over the measurement period. It furthermore assumes that apparent motions due to camera pitch and roll changes are negligible. This is a reasonable assumption for a flight altitude of $74.5 \mathrm{~m}$ and a nadir camera pitch; a $0.2^{\circ}$ drift in pitch over $8.5 \mathrm{~s}$ would result in mapping errors of $0.03-0.04 \mathrm{~m} \mathrm{~s}^{-1}$ depending on the image location. But if we used a pitch of $45^{\circ}$, errors would increase dramatically with values up to $0.25 \mathrm{~m} \mathrm{~s}^{-1}$. Errors due to pitch changes increase linearly with altitude; changes in roll result in errors of comparable magnitude. Under these assumptions, the temporal variability of the apparent currents can be attributed to UAS motions as defined by Eq. (3) and measurement errors with Gaussian distribution. We constructed a least squares optimization that solves for $t_{x}, t_{y}, s$, and $\psi$ by minimizing the current measurements' temporal variability, yielding one set of solutions per analysis period. To constrain the least squares solutions for $s$ and $\psi$, a current mapping mission must consist of at least two stations, and neighboring stations must have partially overlapping camera FOVs.

\section{d. Fixed object and flotsam tracking}

To validate the UAS motion correction and current mapping, we have developed an algorithm that automatically detects and tracks features within the UAS camera FOV, specifically, fixed objects on the RSMAS beach and flotsam drifting on the sea surface. The fixed objects are visible during F1's and F2's first current mapping station; they are used solely to validate the wave-based UAS heading and position correction. The flotsam tracks serve as one of the references for the UAS current maps. To reduce the effects of waves, which we wish to exclude from the tracking, and image noise, we first filter each image with a $3 \times 3$ pixel median filter and then determine the minimum brightness at each pixel over a $0.3 \mathrm{~s}$ period (nine consecutive images). By using the minimum, we exclude contributions from sun glitter and wave breaking. Good features to track have prominent corners; our corner quality measure is the minimal eigenvalue of the covariation matrix of derivatives, which we calculate at each image pixel over $3 \times 3$ pixel blocks. We reject features with minimal eigenvalues below a threshold and features which have stronger features within a minimum distance (Tomasi and Kanade 1991; Jianbo and Tomasi 1994). The remaining features are tracked using a sparse iterative implementation of the Lucas Kanade optical flow method with a $31 \times 31$ pixel search window (Lucas and Kanade 1981; Bouguet et al. 2001). The feature tracking algorithm is applied to each current mapping analysis period; only features that could be tracked for $6.8 \mathrm{~s}(80 \%$ of analysis period) are retained for the validations. Figure 2 shows select fixed object and flotsam tracks from F1's first analysis period.
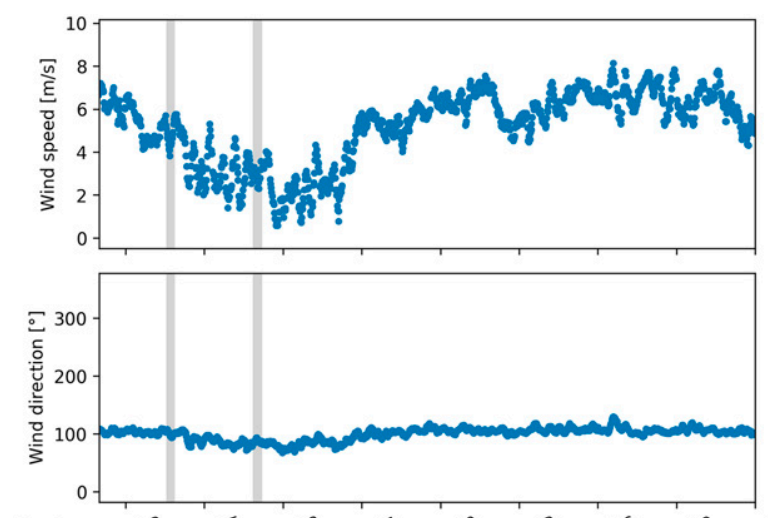

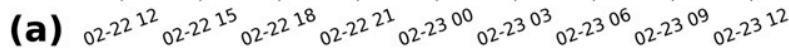
Date Time (EDT)
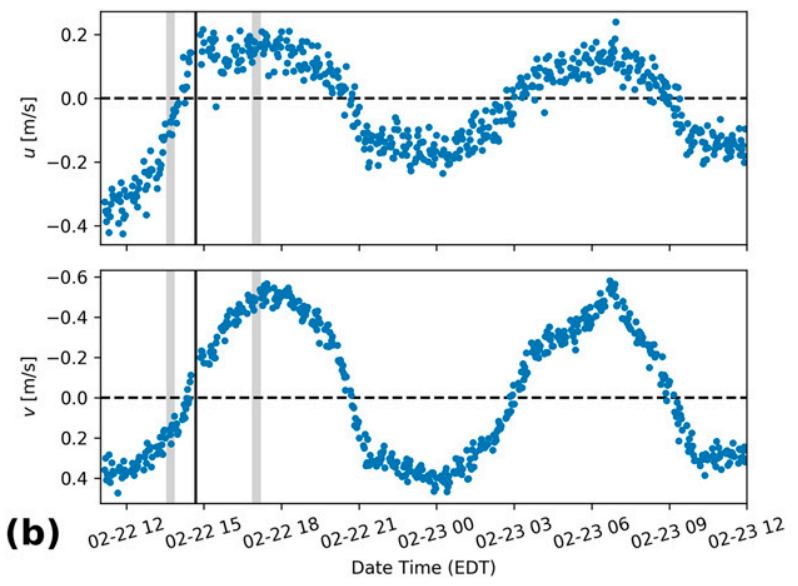

FIG. 4. Time series of (a) the wind speed and direction measured by anemometer and (b) the cross- and along-channel currents measured by ADCP. The F1 and F2 periods are marked by lightgray boxes. The black vertical lines in (b) correspond to the time when the ADCP was repositioned.

\section{Results}

\section{a. Environmental conditions}

Figure 4a shows a time series of the wind speed and direction from 1100 EDT 22 to 1200 EDT 23 February 2018. The winds came consistently from east, with a mean wind speed of $4.6 \mathrm{~m} \mathrm{~s}^{-1}$ (gusts of $8.1 \mathrm{~m} \mathrm{~s}^{-1}$ ) from $99^{\circ}$ at $\mathrm{F} 1$, and a mean wind speed of $2.9 \mathrm{~m} \mathrm{~s}^{-1}$ (gusts of $7.2 \mathrm{~m} \mathrm{~s}^{-1}$ ) from $88^{\circ}$ at F2. Both flights took place under a predominantly clear sky with scattered clouds. Unfortunately, this study lacks measurements of the wave energy density spectrum, but the dominant waves in Bear Cut are typically shorter than $\sim 15 \mathrm{~m}$ or $\sim 3 \mathrm{~s}$. Figure $4 \mathrm{~b}$ shows a time series of the ADCP cross- and along-channel currents for the same period. The currents correspond to each profile's median; the profiles have no clear vertical trends, and the measurements at the individual depth bins are too noisy for reliable interpretation, with mean standard deviations of $0.16 \mathrm{~m} \mathrm{~s}^{-1}$ for each component. The ADCP was moved between $\mathrm{F} 1$ and F2; the flow at both locations has a strong crosschannel component, as confirmed by the nearby drifter tracks in Fig. 1. The currents are dominated by the diurnal tide, with 

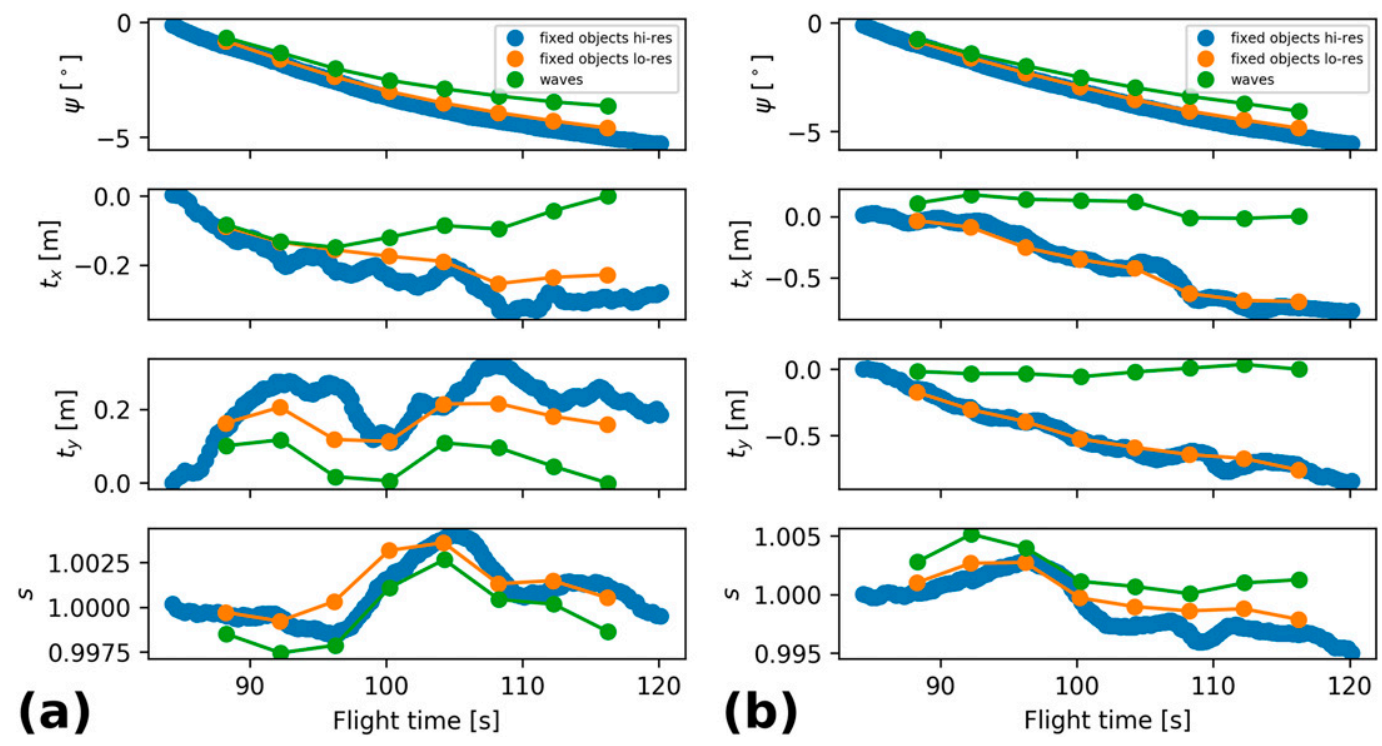

FIG. 5. Time series of the UAS motion expressed in terms of rotation, translation, and uniform scaling for the first current mapping station of (a) F1 and (b) F2. They were derived from the fixed objects tracks at high ( $0.3 \mathrm{~s})$ and low (4s) temporal resolution as well as from the wave signal.

cross-channel currents between -0.43 and $0.24 \mathrm{~m} \mathrm{~s}^{-1}$ and along-channel currents between -0.58 and $0.47 \mathrm{~m} \mathrm{~s}^{-1}$. The figure shows that $\mathrm{F} 1$ coincides with a waning flood current (to Biscayne Bay) and F2 coincides with a near-peak ebb current (to the Atlantic Ocean).

\section{b. Heading and position correction}

The wave-based UAS heading and position correction validation relies on the presence of open water and fixed objects within the camera FOV. The fixed objects must be trackable and near sea level, conditions which are met by the stranded Sargassum, driftwood, etc., on the RSMAS beach. The beach is within the UAS camera FOV during F1's and F2's first current mapping station (see Fig. 2); fixed objects and flotsam were automatically tracked over all 16 analysis periods (see section $3 \mathrm{~d}$ ). We use a least squares optimization to find the affine transformations [as defined by Eq. (3)] that minimize the overall distance of the fixed objects from their starting points. The resulting UAS heading changes $(\psi)$, horizontal motions $\left(t_{x}, t_{y}\right)$, and vertical motions ( $s$, expressed as an expansion) serve as reference for our wave-based solution.

Figures $5 \mathrm{a}$ and $5 \mathrm{~b}$ show time series of $\psi, t_{x}, t_{y}$, and $s$ as derived from the UAS current maps (see section 3c), fixed objects at low temporal resolution (4s), and fixed objects at high temporal resolution $(0.3 \mathrm{~s})$ for F1 and F2. For the fixed object solution at low temporal resolution, we solved for a single $\psi, t_{x}, t_{y}$, and $s$ per analysis period, mirroring one of the limitations of the wave-based approach. As could be expected for F1, based on the "eddy" and fixed object tracks in Fig. 2, all three solutions indicate that the UAS rotated counterclockwise. The wavebased rotation is similar to the fixed object ones, although smaller in magnitude $\left(3.7^{\circ}\right.$ vs $4.6^{\circ}$ and $5.3^{\circ}$ over all analysis periods); interestingly, we found almost identical UAS rotations for F2 $\left(4.1^{\circ}\right.$ vs $4.8^{\circ}$ and $\left.5.6^{\circ}\right)$. For both flights, the reduced temporal resolution resulted in a slight underestimation of the rotation. It should be noted that these heading changes exceed those reported by Holman et al. (2017) and Bergsma et al. (2019) by factors of 2-3. Presently, we do not have an explanation for these discrepancies. Regarding the UAS vertical motion, the three solutions exhibit similar trends for both flights, indicating good agreement. At a height of $74.5 \mathrm{~m}$, scaling factors between 0.995 and 1.005, as observed here, correspond to altitude changes between -0.37 and $0.37 \mathrm{~m}$. The solutions for horizontal motion are more difficult to compare. We had to force the wave-based horizontal motions to a zero mean, as they were insufficiently constrained. Thus, while our method can identify the horizontal motion that departs from the mean, it is blind to any underlying linear trend, as we cannot distinguish a constant horizontal UAS drift from a current. This is why our wave-based solutions for $t_{x}$ and $t_{y}$ missed the linear trends that are evident in the fixed object solutions.

To quantify the performance of our wave-based UAS motion correction, we used its solutions for $\psi, t_{x}, t_{y}$, and $s$ to transform the fixed object tracks. Statistics on the distances between the first and last point of each fixed object track, evaluated separately for F1 and F2, are given in Table 1 . The table furthermore shows distance statistics for the two fixed object solutions and for the case without correction. The mean rectification errors without correction are 0.78 and $0.71 \mathrm{~m}$ for F1 and F2. Not surprisingly, the statistics are best for the highresolution fixed object solution with mean errors of 0.04 and $0.05 \mathrm{~m}$ for $\mathrm{F} 1$ and $\mathrm{F} 2$, or $5.1 \%$ and $7.6 \%$ of the mean rectification errors without correction. The corresponding values for the low-resolution fixed object solution are $0.05 \mathrm{~m}(6.8 \%)$ and $0.09 \mathrm{~m}(12.3 \%)$ and for the wave-based solution are $0.22 \mathrm{~m}$ $(27.7 \%)$ and $0.21 \mathrm{~m}(29.8 \%)$. In other words, our wave-based UAS motion correction improves the image rectification accuracy by a factor of $\sim 3.5$. 
TABLE 1. Image rectification accuracy before and after motion correction based on fixed objects at high ( $0.3 \mathrm{~s})$ and low ( $4 \mathrm{~s})$ temporal resolution as well as based on the wave signal. The statistics are computed from the distances between the first and last point of each fixed object track.

\begin{tabular}{|c|c|c|c|c|c|c|}
\hline & $N$ & Mean (m) & Median (m) & 95th percentile $(\mathrm{m})$ & $\sigma(\mathrm{m})$ & $\operatorname{Max}(\mathrm{m})$ \\
\hline $\mathrm{F} 1$ & 1113 & 0.783 & 0.737 & 1.152 & 0.172 & 1.282 \\
\hline F1, fixed objects hi res & 1113 & 0.040 & 0.026 & 0.124 & 0.042 & 0.253 \\
\hline F1, fixed objects lo res & 1113 & 0.053 & 0.041 & 0.135 & 0.043 & 0.271 \\
\hline F1, waves & 1113 & 0.217 & 0.209 & 0.311 & 0.053 & 0.389 \\
\hline $\mathrm{F} 2$ & 1480 & 0.707 & 0.693 & 0.931 & 0.155 & 1.827 \\
\hline F2, fixed objects hi res & 1480 & 0.054 & 0.032 & 0.147 & 0.101 & 1.165 \\
\hline F2, fixed objects lo res & 1480 & 0.087 & 0.070 & 0.179 & 0.101 & 1.195 \\
\hline F2, waves & 1480 & 0.211 & 0.206 & 0.316 & 0.111 & 1.253 \\
\hline
\end{tabular}

The current maps present an alternative means of validating the wave-based UAS motion correction. Figures $6 a$ and $6 b$ show cross-channel transects of the cross- and along-channel current measurements before and after motion correction for F1. The current mapping stations are color-coded; we expect spatially overlapping measurements from neighboring stations to be in good agreement. The precorrection currents show discontinuities on the order of $0.1 \mathrm{~m} \mathrm{~s}^{-1}$ between current mapping stations, most visibly for the cross-channel component. The UAS motion correction removed these discontinuities and, furthermore, reduced the measurement variability across the entire transect, as evidenced by the currents' narrower spread. The remaining spread is due to spatial variability along the $y$ axis and measurement errors.

To quantify the UAS motion correction's impact on the current measurements, we computed their temporal repeatability before quality control and motion correction, after lenient quality control (similarity threshold of $0.2 \mathrm{~m} \mathrm{~s}^{-1}$ ) but before motion correction, after lenient quality control and motion correction, as well as after strict quality control (similarity threshold of $0.1 \mathrm{~m} \mathrm{~s}^{-1}$ ) and motion correction; results are presented in Table 2 . The lenient quality control removed $0.2 \%$ and $1.6 \%$ of measurements from $\mathrm{F} 1$ and $\mathrm{F} 2$; the strict quality control removed $0.3 \%$ and $3.0 \%$ of measurements. The repeatabilities of the cross- and along-channel current components after lenient quality control but before motion correction are 0.024 and $0.020 \mathrm{~m} \mathrm{~s}^{-1}$ for $\mathrm{F} 1$ and 0.020 and $0.016 \mathrm{~m} \mathrm{~s}^{-1}$ for $\mathrm{F} 2$. After lenient quality control and motion correction, the repeatabilities of both components are $0.005 \mathrm{~m} \mathrm{~s}^{-1}$ for $\mathrm{F} 1$ and $0.009 \mathrm{~m} \mathrm{~s}^{-1}$ for $\mathrm{F} 2$, representing improvements by factors of 1.8-4.8 depending on flight and current component. The strict quality control further improved the repeatabilities for F2 but not those for F1. For comparison, the ADCP's mean temporal repeatabilities (i.e., the standard deviations of the profiles' median values evaluated for each 22 min measurement period) are 0.034 and $0.037 \mathrm{~m} \mathrm{~s}^{-1}$ for the cross- and along-channel components. The drifters have mean temporal repeatabilities of 0.009 and $0.010 \mathrm{~m} \mathrm{~s}^{-1}$ with a measurement period of $15 \mathrm{~s}$.

\section{c. Current mapping}

Having confirmed that the UAS motion correction significantly improves the current measurements' temporal repeatability and image rectification accuracy, our remaining task is to validate the current maps against the reference data. Figure 7 compares the UAS current maps from F1 and F2 with the matching drifter tracks and flotsam vectors (see section $3 \mathrm{~d}$ ). Both the wave- and flotsam-based currents have been corrected for UAS motion; the former represent temporal averages over all available measurements, the latter are based on single analysis periods. The three current products, plotted on
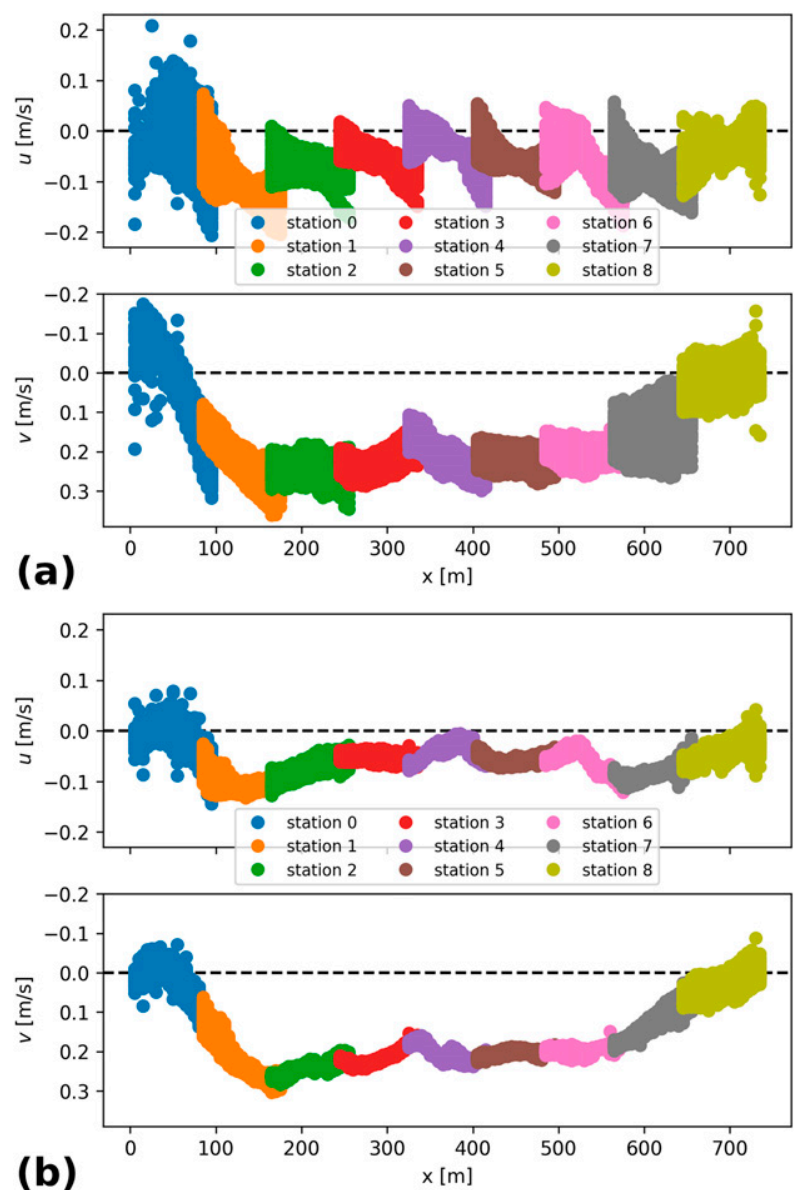

FIG. 6. UAS wave-based cross- and along-channel currents from F1 as a function of the cross-channel coordinate (a) before and (b) after UAS motion correction. The current mapping stations are color-coded. 
TABLE 2. Temporal repeatability of the UAS wave-based crossand along-channel currents for F1 and F2 before quality control and UAS motion correction (MC), after quality control with a similarity threshold of $0.2 \mathrm{~m} \mathrm{~s}^{-1}\left(\mathrm{QC}_{0.2}\right)$ but before $\mathrm{MC}$, after $\mathrm{QC}_{0.2}$ and $\mathrm{MC}$, and after quality control with a similarity threshold of $0.1 \mathrm{~m} \mathrm{~s}^{-1}\left(\mathrm{QC}_{0.1}\right)$ and $\mathrm{MC}$.

\begin{tabular}{|c|c|c|c|}
\hline & $N$ & $\sigma_{u}\left(\mathrm{~m} \mathrm{~s}^{-1}\right)$ & $\sigma_{v}\left(\mathrm{~m} \mathrm{~s}^{-1}\right)$ \\
\hline $\mathrm{F} 1$ & 14134 & 0.025 & 0.021 \\
\hline $\mathrm{F} 1, \mathrm{QC}^{0.2}$ & 14109 & 0.024 & 0.020 \\
\hline $\mathrm{F} 1, \mathrm{QC}^{0.2}, \mathrm{MC}$ & 14109 & 0.005 & 0.005 \\
\hline $\mathrm{F} 1, \mathrm{QC}^{0.1}, \mathrm{MC}$ & 14091 & 0.005 & 0.005 \\
\hline $\mathrm{F} 2$ & 15857 & 0.025 & 0.024 \\
\hline $\mathrm{F} 2, \mathrm{QC}^{0.2}$ & 15598 & 0.020 & 0.016 \\
\hline $\mathrm{F} 2, \mathrm{QC}^{0.2}, \mathrm{MC}$ & 15598 & 0.009 & 0.009 \\
\hline $\mathrm{F} 2, \mathrm{QC}^{0.1}, \mathrm{MC}$ & 15378 & 0.008 & 0.008 \\
\hline
\end{tabular}

the same color scale, are in good qualitative agreement. They confirm the ADCP-based observation that F1 coincided with a waning flood current while F2 coincided with a peaking ebb current (see Fig. 4). The UAS wave-based current maps have maximum currents speeds of 0.31 and $0.72 \mathrm{~m} \mathrm{~s}^{-1}$ for $\mathrm{F} 1$ and $\mathrm{F} 2$. They are spatially coherent with the strongest currents of both flights observed near Virginia Key at cross-channel distances of 100-200 m; a secondary peak was observed near Key Biscayne at a cross-channel distance of $\sim 600 \mathrm{~m}$ during F2. The centerchannel current speeds were relatively weak, with the F1 current map exhibiting a minimum of $0.18 \mathrm{~m} \mathrm{~s}^{-1}$ at $340 \mathrm{~m}$ and the F2 current map exhibiting a minimum of $0.35 \mathrm{~m} \mathrm{~s}^{-1}$ at $280 \mathrm{~m}$; for both flights, the currents close to shore were less than $0.05 \mathrm{~m} \mathrm{~s}^{-1}$. The drifter tracks and flotsam-based currents, although far less comprehensive, support this general description of the Bear Cut flow.

Figure 8 shows scatterplot comparisons between the UAS wave-based current maps and the reference data for both flights combined. The wave-based measurements were bilinearly interpolated to match the locations of the reference measurements. Table 3 shows the corresponding comparison statistics; no statistics are given for the comparison between the wave-based and ADCP currents, as it consists of only two data points. The comparison between the wave- and flotsam-based currents is heavily weighted toward F1 (475 data points during
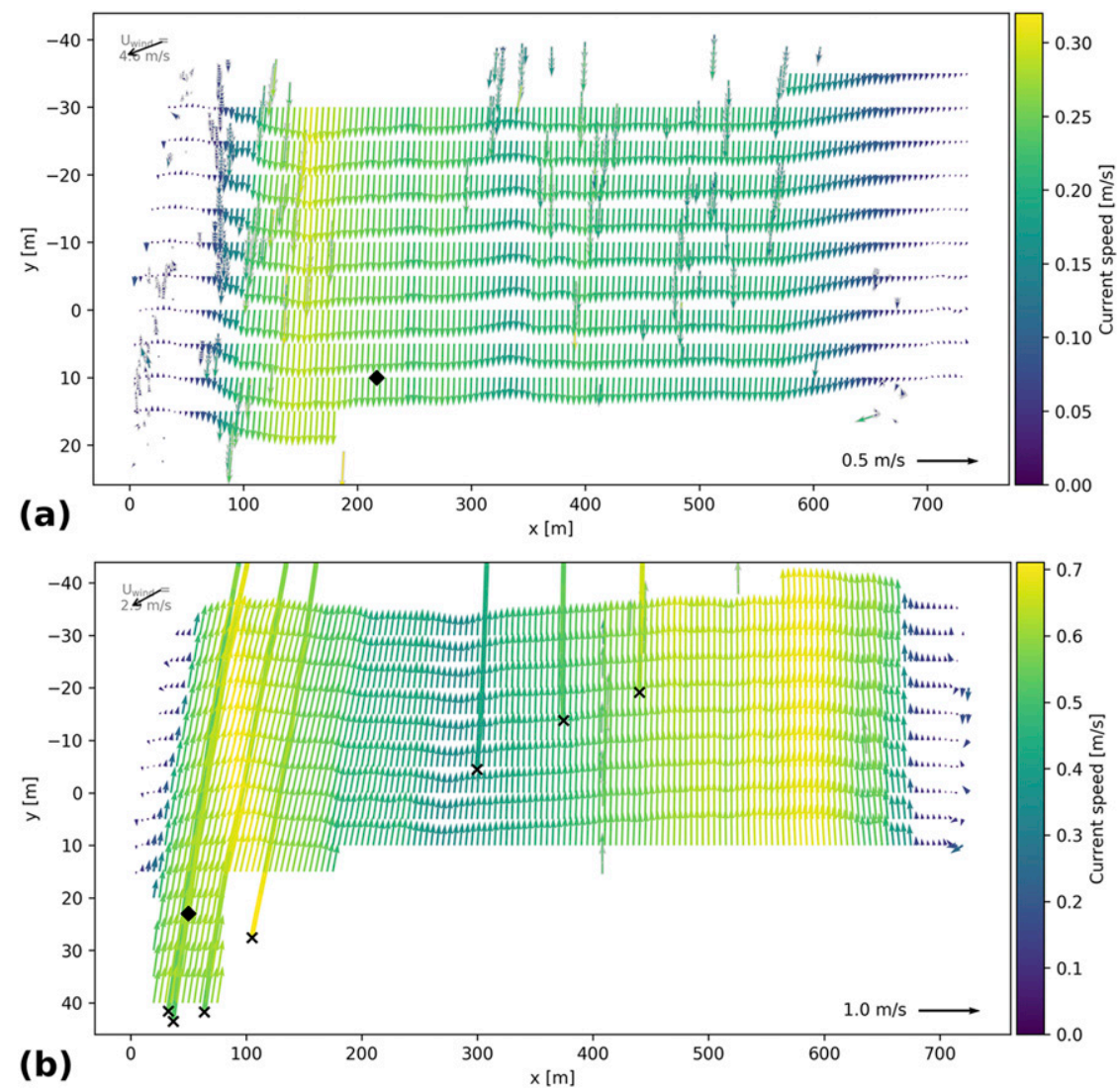

FIG. 7. UAS wave- and flotsam-based currents, marked by colored arrows, from (a) F1 and (b) F2. The flotsam-based currents are plotted with a light-gray edge. The arrow angles were determined using the coordinate system's aspect ratio, i.e., the arrows point from $(x, y)$ to $(x+$ $u, y+v)$. The arrow lengths are proportional to the current speed (with an aspect ratio of 1); arrow keys are given in the bottom right of each panel. The lines mark the drifter tracks, with drifter launch locations marked by crosses. The color bars give the current speeds for all three current products. The ADCP locations are marked by diamonds. 

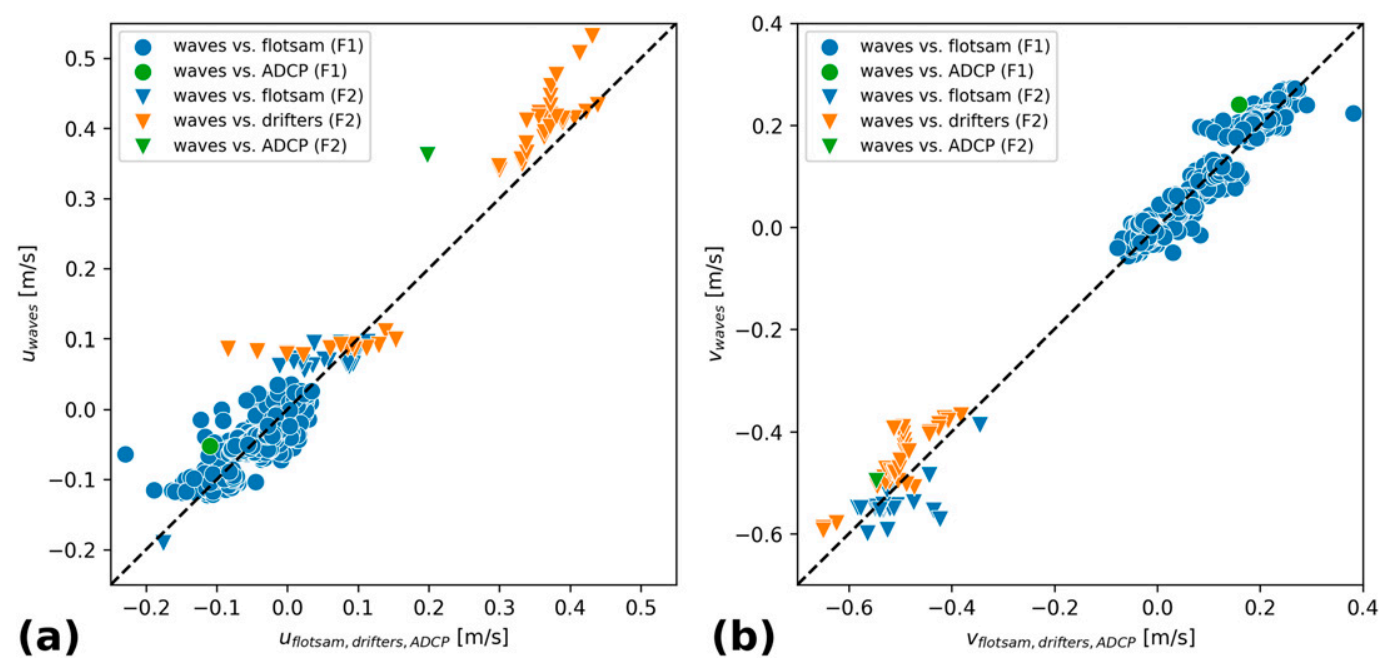

FIG. 8. Scatterplots of the UAS wave- vs flotsam-based, UAS wave-based vs drifter, and UAS wave-based vs ADCP (a) cross- and (b) along-channel currents for F1 and F2.

F1 vs 21 data points during F2); the comparison between the wave-based and drifter currents is limited to F2 (41 data points). The former has explained variances of $87.0 \%$ and $98.5 \%$, standard deviations of 0.025 and $0.028 \mathrm{~m} \mathrm{~s}^{-1}$, and negligible biases for $u$ and $v$. The latter has explained variances of $96.1 \%$ and $82.1 \%$, standard deviations of 0.044 and $0.035 \mathrm{~m} \mathrm{~s}^{-1}$, and biases of 0.038 and $0.048 \mathrm{~m} \mathrm{~s}^{-1}$ for $u$ and $v$. Last, compared with the two collocated ADCP measurements, the wave-based cross- and along-channel currents have biases of 0.058 and $0.082 \mathrm{~m} \mathrm{~s}^{-1}$ during F1 and 0.164 and $0.051 \mathrm{~m} \mathrm{~s}^{-1}$ during F2.

\section{Discussion}

\section{a. Concepts of operation}

This study uses a lower flight altitude $(\sim 74.5 \mathrm{vs} \sim 200 \mathrm{~m})$ and shorter analysis period ( 8.5 vs $60 \mathrm{~s}$ ) than Streßer et al. (2017). A higher flight altitude of $\sim 120 \mathrm{~m}$ (the current legal limit under Federal Aviation Administration rules) would have the advantages of an increased camera FOV and longer hovering periods. Here we chose a lower altitude to 1) minimize risks for small planes and helicopters operating in the area and 2) keep current mapping errors due to unaccounted for pitch and roll changes in check. Similarly, the shorter analysis period was found to be a good compromise between the need for a high SNR (i.e., long analysis period) on the one hand and for a high temporal resolution (i.e., short analysis period) for the UAS heading and position correction on the other hand.

By analyzing the brightness variance of UAS sea surface images as a function of camera pitch, Holman et al. (2017) found that the waves, bandpass filtered between periods of 3 and $18 \mathrm{~s}$, decreased in contrast by a factor of $\sim 4$ as the camera pitch increased from $-15^{\circ}$ to $-45^{\circ}$ (with nadir at $-90^{\circ}$ ). Near horizontal viewing angles furthermore offer a greater camera coverage area, but at the cost of image resolution. Chapman (1981) used a model to show that, depending on sky conditions, the waves' contrast may peak near the horizon, at nadir, within the sun glitter area, or $90^{\circ}$ away from the sun glitter area. Dugan et al. (2001) used a camera pitch of $-30^{\circ}$ for their aircraft-borne current and bathymetry measurements. Their current measurements, however, were limited to the nearshore, where GCPs were available, since their rectified images had a spurious drift of up to $0.2 \mathrm{~m} \mathrm{~s}^{-1}$. Holman et al. (2017) used a pitch of $-40^{\circ}$ to $-15^{\circ}$ to measure bathymetry. As they used GCPs, errors in the camera position and attitude posed no problems. Following the examples of Streßer et al. (2017) and Sun et al. (2019), who used UASs for wave-based current and bathymetry retrieval, respectively, we acquired our UAS images with the camera at nadir. We made this choice because the image rectification and thus the current mapping are more sensitive to camera position and attitude errors at off-nadir viewing angles.

Our UAS heading and position correction requires the UAS to hover during current mapping stations. If the current mapping were based on images from a moving UAS, heading errors would translate into spurious cross-track currents that are proportional to the UAS speed and the sine of the error angle (Lund et al. 2015a). While feasible in principle, this would require position and heading accuracies of $\sim 1 \mathrm{~cm}$ and $0.1^{\circ}$. The former could be accomplished with real-time kinematic GPS (RTK-GPS), limiting the method's applicability to the nearshore (RTK-GPS uses a fixed base station). The latter is nearly impossible with off-the-shelf technology; magnetic compasses are accurate to $1^{\circ}$ at best, DJI's dual antenna GPS compass would require a baseline of $2 \mathrm{~m}$ to achieve $0.1^{\circ}$ accuracy (DJI 2017a).

\section{b. Heading and position correction}

The UAS heading and position correction introduced here improved the image rectification accuracy by a factor of $\sim 3.5$ and the current mapping's temporal repeatability by factors of 1.8-4.8. While very effective, the method has shortcomings: 1) It does not account for changes in camera pitch and roll. We believe this simplification is justified since the P4 camera is 
TABLE 3. Statistical comparison of the UAS wave-based against the flotsam-based and against the drifter currents' cross-channel component, along-channel component, and speed. The drifter comparison also includes statistics for the cross- $\left(U_{\perp}\right)$ and along-wind currents $\left(U_{\|}\right)$.

\begin{tabular}{|c|c|c|c|c|c|c|}
\hline & $N$ & $r$ & $r^{2}$ & $\operatorname{Bias}\left(\mathrm{m} \mathrm{s}^{-1}\right)$ & $\operatorname{RMS}\left(\mathrm{m} \mathrm{s}^{-1}\right)$ & $\sigma\left(\mathrm{m} \mathrm{s}^{-1}\right)$ \\
\hline$u$ (vs flotsam) & 496 & 0.933 & 0.870 & -0.001 & 0.025 & 0.025 \\
\hline$v$ (vs flotsam) & 496 & 0.993 & 0.985 & 0.003 & 0.028 & 0.028 \\
\hline Speed (vs flotsam) & 496 & 0.986 & 0.972 & 0.003 & 0.029 & 0.029 \\
\hline$u$ (vs drifters $)$ & 41 & 0.980 & 0.961 & 0.038 & 0.058 & 0.044 \\
\hline$v$ (vs drifters) & 41 & 0.906 & 0.821 & 0.048 & 0.059 & 0.035 \\
\hline Speed (vs drifters) & 41 & 0.966 & 0.933 & -0.020 & 0.038 & 0.032 \\
\hline$U_{\perp}($ vs drifters $)$ & 41 & 0.974 & 0.948 & -0.004 & 0.038 & 0.038 \\
\hline$U_{\|}($vs drifters $)$ & 41 & 0.970 & 0.941 & 0.061 & 0.074 & 0.041 \\
\hline
\end{tabular}

gimbal stabilized, and Holman et al. (2017) and Bergsma et al. (2019) found the pitch and roll of its predecessor to have relatively low standard deviations between $0.17^{\circ}$ and $0.31^{\circ}$. We noticed, however, that the horizon line within a subsample of our UAS imagery was tilted by $\sim 1^{\circ}$, although the P4's IMU and gimbal recorded a roll of $\sim 0^{\circ}$. A bias in the camera roll causes image rectification errors that could affect the current mapping. This may explain why the least squares solutions for $t_{x}$ and $t_{y}$ were poorly constrained and had to be forced to a zero mean. 2) It does not account for errors in the absolute camera position and attitude. According to the manufacturer, the GPS positioning accuracy is $1.5 \mathrm{~m}$ horizontally and $0.5 \mathrm{~m}$ vertically, the gimbal's angular control accuracy is $0.02^{\circ}$ (DJI 2017b). As noted under the previous point, errors in camera position and attitude could affect the current mapping. 3) Its temporal resolution matches that of the current maps (4s), with each set of solutions being based on an analysis period ( $8.5 \mathrm{~s})$. Results from Holman et al. (2017) and Bergsma et al. (2019) indicate that changes in camera position and attitude occur at time scales of 1 min or longer, suggesting that our method's temporal resolution is sufficient.

\section{c. Current mapping}

The UAS wave-based currents' effective depth is approximately $0.03 \mathrm{~m}$ (see section $3 \mathrm{~b}$ ), the flotsam-based currents correspond to the upper few centimeters of the ocean, the drifters' center of draft is $0.4 \mathrm{~m}$, and the ADCP currents represent the median across the entire water column. The statistical comparison between the wave- and flotsam-based currents yielded the best agreement (see Table 3); this could be expected since both are UAS based (i.e., errors due to residual UAS motions cancel each other out) and sample approximately the same water column. The bias in the drifter comparison can be explained by the wave-based measurements' shallower effective depth. After rotating the wave-based and drifter currents into cross- and along-wind components, with the crosswind axis positive to the left and the alongwind axis positive downwind, the wave-based currents' biases are -0.004 and $0.061 \mathrm{~m} \mathrm{~s}^{-1}$ (see Table 3 ). This conforms with the physical expectation that winds and waves are driving an approximately downwind current that decays with increasing depth (e.g., Lewis and Belcher 2004; Laxague et al. 2018). The relatively large biases in the comparison between the wave-based and ADCP currents could also be due to wind- and wave-driven vertical current shear (see section 4c); the cross- and along-wind current biases are -0.033 and $0.095 \mathrm{~m} \mathrm{~s}^{-1}$ during $\mathrm{F} 1$ and 0.085 and $0.149 \mathrm{~m} \mathrm{~s}^{-1}$ during F2. But it must be noted that the two ADCP profiles have no clear vertical trends and are noisy with standard deviations ranging from 0.123 to $0.136 \mathrm{~m} \mathrm{~s}^{-1}$. Also, two drifters passed over the ADCP during F2 (see Fig. 1); compared with either drifter measurement, the wave-based current is biased by only $\sim 0.03 \mathrm{~m} \mathrm{~s}^{-1}$. These findings suggest that the differences between the wave-based and ADCP currents is due to a combination of vertical shear and large scatter in the ADCP data.

As an alternative to the least squares fit method used here, one can solve for the current by maximizing the spectral energy on the dispersion shell (Serafino et al. 2010). Streßer et al. (2017) implemented this method by defining a discrete number of dispersion shells (i.e., possible currents), integrating the spectral energy on each shell, and selecting the current associated with the maximum. This method may be less prone to errors, since it does not explicitly identify the wave signal within the spectrum. However, by focusing on the most energetic part of the spectrum, it risks missing the wave signal's high wavenumber components. What is more, being a "brute force" method, it is computationally more expensive than the least squares fit method.

\section{d. Future research}

There are several avenues for future research: 1) The quality of the current measurements is likely to increase with SNR, but our understanding of the optimal wave viewing angles remains incomplete. More field work is needed to determine the optimal camera viewing angle as a function of sky condition, ocean turbidity, and surface wave period. 2) How do errors in the absolute camera position and attitude affect the current mapping accuracy? This question needs to be answered for different viewing angles; we expect more severe impacts at off-nadir angles. 3) To measure currents at off-nadir angles, we must account for apparent motions due to changes in camera pitch and roll. One option is to replace the affine transformation [Eq. (3)] used by our method with the pinhole camera model [Eq. (2)], which would allow us to solve for all 6 UAS degrees of freedom. Alternatively, we could use a horizon-tracking method to invert camera pitch and roll (e.g., Schwendeman and Thomson 2015). 4) The current measurements' effective depth increases with wavelength; by performing the current fit as a 
function of wavenumber, we obtain a vertical current profile. This technique has already been applied to MR (Lund et al. 2015b), polarimetric (Laxague et al. 2018), and thermal (Laxague and Zappa 2020) image series; we plan to extend it to UAS optical image series, keeping in mind that the shortest waves ( $k>\sim 100 \mathrm{rad} \mathrm{m}^{-1}$ or wavelengths $L<\sim 0.06 \mathrm{~m}$ ) may be bound to longer waves (Laxague and Zappa 2020; Plant et al. 1999). 5) The wave periods we observed in this study $(<3 \mathrm{~s})$ are short for typical coastal environments. Surface gravity waves longer than our analysis period $(8.5 \mathrm{~s})$ could introduce image rectification errors that would in turn reduce the accuracy of our UAS heading and position correction as well as current mapping. More research is needed to investigate our method's performance in presence of longer surface gravity waves.

\section{Conclusions}

This study uses optical surface wave images from a low-cost off-the-shelf UAS to create accurate and high-resolution current maps. Unaccounted for changes in the UAS camera heading and position cause a spurious drift in the rectified UAS images, worsening the current mapping accuracy. We present a novel UAS heading and position correction method that relies on the wave signal only. We mapped the ebb and flood flow across the $\sim 700$-m-wide Bear Cut channel at spatiotemporal resolutions of $5 \mathrm{~m}$ and $4 \mathrm{~s}$, using only $\sim 10 \mathrm{~min}$ of data from two 15 and 17 min flights. The UAS heading and position correction improved the image rectification accuracy and the current measurements' temporal repeatability by factors of $\sim 2-5$. We validated the UAS wave-based current maps using drifter tracks, ADCP measurements, and UAS flotsam tracks. The UAS wave-based current maps have temporal repeatabilities of $<0.01 \mathrm{~m} \mathrm{~s}^{-1}$, comparing favorably to the ADCP and drifter measurements. The RMS errors of the UAS wave-based crossand along-channel currents are better than $0.03 \mathrm{~m} \mathrm{~s}^{-1}$ for our comparison with the flotsam tracks and better than $0.06 \mathrm{~m} \mathrm{~s}^{-1}$ for our comparison with the drifter measurements. The wavebased currents correspond to shallower depths $(\sim 0.03 \mathrm{~m})$ than the drifters $(0.4 \mathrm{~m})$. The UAS currents have an along-wind bias of $0.06 \mathrm{~m} \mathrm{~s}^{-1}$, indicating significant near-surface vertical shear; the standard deviations from the UAS-drifter comparison are $\sim 0.04 \mathrm{~m} \mathrm{~s}^{-1}$. Thus, they have an accuracy that approaches that of traditional in situ sensors. And since the UAS motion correction and current mapping are wave-based (i.e., no GCPs are required), they can be applied anywhere in the world's oceans, offering unparalleled opportunities to study rip currents, frontal instabilities, submesoscale eddies, or ice edge dynamics. The current maps can be easily processed to yield kinematic quantities such as shear, vorticity, and divergence; divergence zones play an important role for air-sea gas exchange and ocean carbon dioxide storage (e.g., Bracco et al. 2019). The method could prove equally useful for environmental monitoring, such as oil spill tracking or river discharge measurements.

Acknowledgments. BL and HCG acknowledge support from the U.S. Office of Naval Research under Grants N0001419-1-2514 and N00014-13-1-0288. The Bear Cut experiment was made possible by a grant from the Gulf of Mexico Research Initiative. The authors are grateful to the three anonymous reviewers, whose comments have improved this paper significantly.

Data availability statement. The drifter, ADCP, and UAS current data are publicly available through the Gulf of Mexico Research Initiative Information and Data Cooperative (GRIIDC) at https://data.gulfresearchinitiative.org (DOI: 10.7266/ XYFYQHAX).

\section{REFERENCES}

Bell, P. S., 1999: Shallow water bathymetry derived from an analysis of X-band marine radar images of waves. Coastal Eng., 37, 513-527, https://doi.org/10.1016/S0378-3839(99)00041-1.

_ , and J. C. Osler, 2011: Mapping bathymetry using X-band marine radar data recorded from a moving vessel. Ocean Dyn., 61, 2141-2156, https://doi.org/10.1007/s10236-011-0478-4.

Bergsma, E. W. J., D. Conley, M. Davidson, and T. O'Hare, 2016: Video-based nearshore bathymetry estimation in macro-tidal environments. Mar. Geol., 374, 31-41, https://doi.org/10.1016/ j.margeo.2016.02.001.

_ R. Almar, L. P. M. de Almeida, and M. Sall, 2019: On the operational use of UAVs for video-derived bathymetry. Coastal Eng., 152, 103527, https://doi.org/10.1016/j.coastaleng.2019.103527.

Bouguet, J.-Y., 2001: Pyramidal implementation of the affine Lucas Kanade feature tracker description of the algorithm. Intel Corporation Microprocessor Research Labs Rep., 9 pp.

_- 2004: Camera calibration toolbox for MATLAB. California Institute of Technology, http://www.vision.caltech.edu/bouguetj/ calib_doc/.

Bracco, A., G. Liu, and D. Sun, 2019: Mesoscale-submesoscale interactions in the Gulf of Mexico: From oil dispersion to climate. Chaos Solitons Fractals, 119, 63-72, https:/doi.org/ 10.1016/j.chaos.2018.12.012.

Brodie, K. L., B. L. Bruder, R. K. Slocum, and N. J. Spore, 2019: Simultaneous mapping of coastal topography and bathymetry from a lightweight multicamera UAS. IEEE Trans. Geosci. Remote Sens., 57, 6844-6864, https://doi.org/10.1109/ TGRS.2019.2909026.

Brouwer, R. L., M. A. De Schipper, P. F. Rynne, F. J. Graham, A. J. Reniers, and J. H. MacMahan, 2015: Surfzone monitoring using rotary wing unmanned aerial vehicles. J. Atmos. Oceanic Technol., 32, 855-863, https://doi.org/10.1175/JTECH-D-1400122.1.

Campana, J., E. J. Terrill, and T. de Paolo, 2016: The development of an inversion technique to extract vertical current profiles from X-band radar observations. J. Atmos. Oceanic Technol., 33, 2015-2028, https://doi.org/10.1175/JTECH-D-15-0145.1.

,-- , and $\longrightarrow, 2017$ : A new inversion method to obtain upper-ocean current-depth profiles using X-band observations of deep-water waves. J. Atmos. Oceanic Technol., 34, 957-970, https://doi.org/10.1175/JTECH-D-16-0120.1.

Chapman, R., 1981: Visibility of rms slope variations on the sea surface. Appl. Opt., 20, 1959-1966, https://doi.org/10.1364/ AO.20.001959.

—_, and G. Irani, 1981: Errors in estimating slope spectra from wave images. Appl. Opt., 20, 3645-3652, https://doi.org/10.1364/ AO.20.003645.

Chickadel, C., R. A. Holman, and M. H. Freilich, 2003: An optical technique for the measurement of longshore currents. J. Geophys. Res., 108, 3364, https://doi.org/10.1029/2003JC001774. 
Chirayath, V., and S. A. Earle, 2016: Drones that see through waves-Preliminary results from airborne fluid lensing for centimetre-scale aquatic conservation. Aquat. Conserv., 26, 237-250, https://doi.org/10.1002/aqc.2654.

Colomina, I., and P. Molina, 2014: Unmanned aerial systems for photogrammetry and remote sensing: A review. ISPRS J. Photogramm. Remote Sens., 92, 79-97, https://doi.org/ 10.1016/j.isprsjprs.2014.02.013.

Dean, R. G., and R. A. Dalrymple, 1991: Water Wave Mechanics for Engineers and Scientists. World Scientific, 368 pp.

Dérian, P., and R. Almar, 2017: Wavelet-based optical flow estimation of instant surface currents from shore-based and UAV videos. IEEE Trans. Geosci. Remote Sens., 55, 5790-5797, https://doi.org/10.1109/TGRS.2017.2714202.

DJI, 2017a: D-RTK user manual. DJI Doc., 17 pp.

— 2017b: Phantom 4 Pro/Pro+ user manual. DJI Doc., 69 pp.

Dugan, J. P., and C. C. Piotrowski, 2003: Surface current measurements using airborne visible image time series. Remote Sens. Environ., 84, 309-319, https://doi.org/10.1016/S00344257(02)00116-5.

— — - and J. Z. Williams, 2001: Water depth and surface current retrievals from airborne optical measurements of surface gravity wave dispersion. J. Geophys. Res., 106, $16903-$ 16 915, https://doi.org/10.1029/2000JC000369.

Ha, E.-C., 1979: Remote sensing of ocean surface current and current shear by HF backscatter radar. DTIC Doc. D415-1, 141 pp.

Heikkila, J., and O. Silven, 1997: A four-step camera calibration procedure with implicit image correction. Proc. IEEE Computer Society Conf. on Computer Vision and Pattern Recognition, San Juan, PR, Institute of Electrical and Electronics Engineers, 1106-1112, https://doi.org/10.1109/CVPR.1997.609468.

Holman, R. A., and R. Guza, 1984: Measuring run-up on a natural beach. Coastal Eng., 8, 129-140, https://doi.org/10.1016/03783839(84)90008-5.

— of Argus. Coastal Eng., 54, 477-491, https://doi.org/10.1016/ j.coastaleng.2007.01.003.

_ - N. G. Plant, and T. Holland, 2013: cBathy: A robust algorithm for estimating nearshore bathymetry. J. Geophys. Res. Oceans, 118, 2595-2609, https://doi.org/10.1002/jgrc.20199.

— K. L. Brodie, and N. J. Spore, 2017: Surf zone characterization using a small quadcopter: Technical issues and procedures. IEEE Trans. Geosci. Remote Sens., 55, 2017-2027, https://doi.org/10.1109/TGRS.2016.2635120.

Honegger, D. A., M. C. Haller, and R. A. Holman, 2019: Highresolution bathymetry estimates via $\mathrm{X}$-band marine radar: 1. Beaches. Coastal Eng., 149, 39-48, https://doi.org/10.1016/ j.coastaleng.2019.03.003.

Jähne, B., and K. S. Riemer, 1990: Two-dimensional wave number spectra of small-scale water surface waves. J. Geophys. Res., 95, 11 531-11 546, https://doi.org/10.1029/JC095iC07p11531.

Jianbo, S., and C. Tomasi, 1994: Good features to track. Proc. IEEE Conf. on Computer Vision and Pattern Recognition, Seattle, WA, IEEE, 593-600, https://doi.org/10.1109/CVPR.1994.323794.

Jung, D., J.-S. Lee, J.-Y. Baek, J. Nam, Y.-H. Jo, K.-M. Song, and Y. I. Cheong, 2019: High temporal and spatial resolutions of sea surface current from low-altitude remote sensing. J. Coastal Res., 90 (Suppl. 1), 282-288, https://doi.org/10.2112/ SI90-035.1.

Laxague, N. J. M., and C. J. Zappa, 2020: Observations of mean and wave orbital flows in the ocean's upper centimetres. J. Fluid Mech., 887, A10, https://doi.org/10.1017/jfm.2019.1019.
- , and Coauthors, 2018: Observations of near-surface current shear help describe oceanic oil and plastic transport. Geophys. Res. Lett., 45, 245-249, https://doi.org/10.1002/ 2017GL075891.

Lewis, D., and S. Belcher, 2004: Time-dependent, coupled, Ekman boundary layer solutions incorporating Stokes drift. Dyn. Atmos. Oceans, 37, 313-351, https://doi.org/10.1016/ j.dynatmoce.2003.11.001.

Lippmann, T. C., and R. A. Holman, 1989: Quantification of sand bar morphology: A video technique based on wave dissipation. J. Geophys. Res., 94, 995-1011, https://doi.org/10.1029/ JC094iC01p00995.

Lucas, B. D., and T. Kanade, 1981: An iterative image registration technique with an application to stereo vision. Proc. Seventh Int. Joint Conf. on Artificial Intelligence, Vancouver, BC, Canada, IJCAI, 674-679.

Lund, B., H. C. Graber, K. G. Hessner, and N. J. Williams, 2015a: On shipboard marine X-band radar near-surface current “calibration." J. Atmos. Oceanic Technol., 32, 1928-1944, https://doi.org/10.1175/JTECH-D-14-00175.1.

,,-- H. Tamura, C. O. Collins III, and S. M. Varlamov, 2015b: A new technique for the retrieval of near-surface vertical current shear from marine X-band radar images. J. Geophys. Res. Oceans, 120, 8466-8486, https://doi.org/ 10.1002/2015JC010961.

— , and Coauthors, 2018: Near-surface current mapping by shipboard marine X-band radar: A validation. J. Atmos. Oceanic Technol., 35, 1077-1090, https://doi.org/10.1175/ JTECH-D-17-0154.1.

_ , and Coauthors, 2020: Marine X-band radar currents and bathymetry: An argument for a wave number-dependent retrieval method. J. Geophys. Res. Oceans, 125, e2019JC015618, https://doi.org/10.1029/2019JC015618.

MacMahan, J., R. Vennell, R. Beatson, J. Brown, and A. Reniers, 2012: Divergence-free spatial velocity flow field interpolator for improving measurements from ADCP-equipped small unmanned underwater vehicles. J. Atmos. Oceanic Technol., 29, 478-484, https://doi.org/10.1175/JTECH-D11-00084.1.

Mancini, F., M. Dubbini, M. Gattelli, F. Stecchi, S. Fabbri, and G. Gabbianelli, 2013: Using unmanned aerial vehicles (UAV) for high-resolution reconstruction of topography: The structure from motion approach on coastal environments. Remote Sens., 5, 6880-6898, https://doi.org/10.3390/ rs5126880.

Martínez-Carricondo, P., F. Agüera-Vega, F. Carvajal-Ramírez, F.-J. Mesas-Carrascosa, A. García-Ferrer, and F.-J. PérezPorras, 2018: Assessment of UAV-photogrammetric mapping accuracy based on variation of ground control points. Int. J. Appl. Earth Obs. Geoinf., 72, 1-10, https://doi.org/10.1016/ j.jag.2018.05.015.

Nortek, 2017: The comprehensive manual. Nortek Doc., 153 pp.

Novelli, G., C. M. Guigand, C. Cousin, E. H. Ryan, N. J. M. Laxague, H. Dai, B. K. Haus, and T. M. Özgökmen, 2017: A biodegradable surface drifter for ocean sampling on a massive scale. J. Atmos. Oceanic Technol., 34, 2509-2532, https:// doi.org/10.1175/JTECH-D-17-0055.1.

Pearce, S., and Coauthors, 2020: An evaluation of image velocimetry techniques under low flow conditions and high seeding densities using unmanned aerial systems. Remote Sens., 12, 232, https://doi.org/10.3390/rs12020232.

Piotrowski, C. C., and J. P. Dugan, 2002: Accuracy of bathymetry and current retrievals from airborne optical time-series 
imaging of shoaling waves. IEEE Trans. Geosci. Remote Sens., 40, 2606-2618, https://doi.org/10.1109/TGRS.2002.807578.

Plant, N. G., and R. A. Holman, 1997: Intertidal beach profile estimation using video images. Mar. Geol., 140, 1-24, https:// doi.org/10.1016/S0025-3227(97)00019-4.

Plant, W. J., and G. Farquharson, 2012: Origins of features in wave number-frequency spectra of space-time images of the ocean. J. Geophys. Res., 117, C06015, https://doi.org/10.1029/ 2012JC007986.

—, W. C. Keller, V. Hesany, T. Hara, E. Bock, and M. A. Donelan, 1999: Bound waves and Bragg scattering in a windwave tank. J. Geophys. Res., 104, 3243-3263, https://doi.org/ 10.1029/1998JC900061.

Plass, G. N., G. W. Kattawar, and J. A. Guinn, 1976: Radiance distribution over a ruffled sea: Contributions from glitter, sky, and ocean. Appl. Opt., 15, 3161-3165, https://doi.org/10.1364/AO.15.003161.

Rascle, N., J. Molemaker, L. Marié, F. Nouguier, B. Chapron, B. Lund, and A. Mouche, 2017: Intense deformation field at oceanic front inferred from directional sea surface roughness observations. Geophys. Res. Lett., 44, 5599-5608, https:// doi.org/10.1002/2017GL073473.

Rogers, W. E., and D. W. C. Wang, 2007: Directional validation of wave predictions. J. Atmos. Oceanic Technol., 24, 504-520, https://doi.org/10.1175/JTECH1990.1.

Schwendeman, M., and J. Thomson, 2015: A horizon-tracking method for shipboard video stabilization and rectification. J. Atmos. Oceanic Technol., 32, 164-176, https://doi.org/10.1175/ JTECH-D-14-00047.1.

Seemann, J., F. Ziemer, and C. M. Senet, 1997: A method for computing calibrated ocean wave spectra from measurements with a nautical X-band radar. OCEANS '97. MTS/IEEE Conf. Proc., Halifax, NS, Canada, IEEE, 1148-1154, https://doi.org/ 10.1109/OCEANS.1997.624154.

Senet, C. M., J. Seemann, and F. Ziemer, 2001: The near-surface current velocity determined from image sequences of the sea surface. IEEE Trans. Geosci. Remote Sens., 39, 492-505, https://doi.org/10.1109/36.911108.

Serafino, F., C. Lugni, and F. Soldovieri, 2010: A novel strategy for the surface current determination from marine $\mathrm{X}$-band radar data. IEEE Geosci. Remote Sens. Lett., 7, 231-235, https:// doi.org/10.1109/LGRS.2009.2031878.

Smeltzer, B. K., E. Æsøy, A. Ådnøy, and S. Å. Ellingsen, 2019: An improved method for determining near-surface currents from wave dispersion measurements. J. Geophys. Res. Oceans, 124, 8832-8851, https://doi.org/10.1029/2019JC015202.

Stewart, R. H., and J. W. Joy, 1974: HF radio measurements of surface currents. Deep-Sea Res. Oceanogr. Abstr., 21, 10391049, https://doi.org/10.1016/0011-7471(74)90066-7.

Streßer, M., R. Carrasco, and J. Horstmann, 2017: Video based estimation of surface currents using a low-cost quadcopter. IEEE Geosci. Remote Sens. Lett., 14, 2027-2031, https:// doi.org/10.1109/LGRS.2017.2749120.

Sun, S.-H., W.-L. Chuang, K.-A. Chang, J. Young Kim, J. Kaihatu, T. Huff, and R. Feagin, 2019: Imaging-based nearshore bathymetry measurement using an unmanned aircraft system. J. Waterw. Port Coastal Ocean Eng., 145, 04019002, https:// doi.org/10.1061/(ASCE)WW.1943-5460.0000502.

Tauro, F., M. Porfiri, and S. Grimaldi, 2016: Surface flow measurements from drones. J. Hydrol., 540, 240-245, https:// doi.org/10.1016/j.jhydrol.2016.06.012.

Tomasi, C., and T. Kanade, 1991: Detection and tracking of point features. Carnegie Mellon University Tech. Rep. CMU-CS91-132, 22 pp.

Turner, I. L., M. D. Harley, and C. D. Drummond, 2016: UAVs for coastal surveying. Coastal Eng., 114, 19-24, https://doi.org/ 10.1016/j.coastaleng.2016.03.011.

VC Technology, 2020: Litchi. VC Technology, https://flylitchi.com/. Walker, R. E., 1994: Marine Light Field Statistics. Wiley, 675 pp.

Wang, J., F. Shi, J. Zhang, and Y. Liu, 2008: A new calibration model of camera lens distortion. Pattern Recognit., 41, 607615, https://doi.org/10.1016/j.patcog.2007.06.012.

Young, I. R., W. Rosenthal, and F. Ziemer, 1985: A three-dimensional analysis of marine radar images for the determination of ocean wave directionality and surface currents. J. Geophys. Res., 90 , 1049-1059, https://doi.org/10.1029/JC090iC01p01049.

Zhang, Z., 2000: A flexible new technique for camera calibration. IEEE Trans. Pattern Anal. Mach. Intell., 22, 1330-1334, https:// doi.org/10.1109/34.888718. 